\title{
PENANAMAN NILAI-NILAI KARAKTER SOSIAL SISWA DALAM PENDIDIKAN KEWARGANEGARAAN DAN IPS DALAM KONTEKS PERPSPEKTIF GLOBAL
}

\author{
Tetep \\ Pendidikan Teknologi Informasi STKIP Garut \\ Jl. Pahlawan no 32 Garut \\ Tevs.stkipgarut32@gmail.com
}

\begin{abstract}
The 21st century is a major challenge for the development of general education in preparing young people in the nation and the wider life without limits. Education became the center of the adjustment of each individual role as the public face of the world today. Global perspective becomes an important education is taught by any educational institution in order to give birth to a generation that is able to compete in the global life without losing its local characteristics. Social character student that grows naturally in the local life will become a symbol of strength and intelligence implementation of local values developed in the global life through education system. Civic and social studies education as subject which cannot be relased to the developing and changes of society. Civic and social studies educatioan has a major role in bridging of social character education for the student to be humanize.
\end{abstract}

Keywords : global perspective education, social character, humanize.

\section{Pendahuluan}

Abad 21 merupakan era perkembangan masyarakat global yang telah mengecilkan peran setiap negara di dunia, disebabkan oleh semakin dekatnya jarak pandang antar Negara, tidak ada lagi batas-batas budaya dan norma yang absolut. Permasalahan yang semakin komplek menuntut peranan pendidikan yang optimal dalam menyiapkan sumber daya manusia terdidik dan profesional, mampu bersaing, dan memiliki karakter dan jati diri kebangsaan yang tegas.

Fenomena perkembangan pesat Abad ke-21 telah ditandai dengan perubahan berbagai bidang kehidupan, seperti timbulnya ledakan penduduk, ledakan ilmu pengetahuan, dan ledakan teknologi. Hal tersebut menimbulkan berbagai masalah di dalam masyarakat seperti:

1. Permasalahan yang menyangkut pengorganisasian antara lain di bidang pemerintahan, perundang-undangan, pendidikan, penyediaan keperluan hidup, kesehatan, dan kesejahteraan.

2. Ketegangan-ketegangan di dalam masyarakat baik dalam arti psikis maupun fisik (Misalnya keseimbangan lingkungan, polusi, dan masalah lalu lintas).

3. Masalah pertentangan dan kekaburan nilai.

Akibat dari hal-hal tersebut terjadi gejala kehilangan pandangan menyeluruh, timbulnya spesialisasi yang makin intensif di bidang ilmu pengetahuan, misalnya mengakibatkan ketidakpastian diri, terampas rasa identitas individu, kehilangan nilai-nilai sosial dan tujuan etis.

Dalam bukunya yang berjudul Getting to the twenty century : Voluntary 
Action and the Global Agenda (1990), David Korten mengatakan bahwa dalam era abad 21 ini merupakan era krisis yang akan menimpa banyak negara di belahan dunia ini, baik negara maju maupun negara-negara berkembang. Krisis berat itu ditengarai sebagai dampak dari tiga masalah utama yang terjadi dalam dasawarsa tahun 1980an, yaitu (a) kemiskinan, (b) kerusakan lingkungan hidup, dan (c) penggunaan tindakan kekerasan (violence) dalam memecahkan konflik. Tidak hanya pemerintah atau negara yang dituntut untuk mampu memecahkan krisis tersebut, melainkan perlunya keterlibatan pihak lain untuk bersama-sama mencari solusi atas masalah atau krisis itu.

Sekolah merupakan salah satu lembaga pendidikan yang mengemban tugas mempersiapkan SDM yang berkualitas. Sekolah dalam hal ini tidak hanya dibebani untuk mengembangkan kemampuan siswa dalam hal ranah kognitifnya saja, akan tetapi juga ranah afektif dan psikomotor. Apalah gunanya seorang anak yang kemampuan kognitif lebih, tetapi tidak didukung dengan sikap (afektif) dan psikomotor yang baik pula. Dapat terjadi dengan kemampuannya yang tinggi itu justru disalahgunakan untuk hal-hal yang tidak sesuai dengan nilai-nilai yang berlaku dalam masyarakat. Sekolah merupakan sarana utama dalam mengarahkan value education yang merupakan hal terpenting untuk diberikan kepada peserta didik. Jika mengacu kepada apa yang tertulis dalam PP No. 19 Tahun 2005 jelas bahwa salah satu unsur yang harus ada dalam kurikulum pendidikan baik pendidikan umum, kejuruan, dan khusus pada jenjang pendidikan dasar dan menengah berkaitan dengan pendidikan nilai.

Mengacu pada kenyataan di atas maka melalui perkembangan global dan menjamurnya social cyber media, maka bagaimana sekolah mampu memanfaatkan perkembangan global itu dalam membentuk karakter sosial siswa, sehingga kecenderungan globalisasi ini tidak menghilangkan nilai-nilai sosial dan nilainilai etis. Secara filosofis bisa menjadi momentum dalam membentuk karakter sosial peserta didik ke depan melalui pemanfaatan sumber-sumber yang ada.

\section{Pendidikan Perspektif Global dalam Konteks PKn dan PIPS}

Dalam Perspektif global Indonesia sekarang ini sudah harus mempersiapkan para murid untuk memasuki abad yang akan datang yang penuh dengan tantangan dengan adanya proses globalisme. Terlebih lagi sistem ekonomi dan perdagangan dunia sekarang ini semakin terbuka dan akan meningkat di masa yang akan datang menunjukkan arti pentingnya belajar perspektif global.

Istilah yang paling tepat untuk perspektif global adalah "global perspectives in education" atau disingkat dengan global education. Di indonesia disebut dengan istilah perspektif global dengan menekankan pada empat hal pokok yaitu: kesadaran terhadap perspektif global, sistem-sistem global, sejarah global, dan saling pengertian terhadap budaya lain.

Menurut Kamus Besar Bahasa Indonesia, edisi ke tiga tahun 2001, global diartikan secara umum dan keseluruhan, secara bulat, secara garis besar, meliputi seluruh dunia. Globalisasi artinya proses masuknya ke ruang lingkup dunia, mengglobal artinya mendunia. Globalisme adalah paham kebijakan nasional yang memperlakukan seluruh dunia sebagai lingkungan yang layak diperhitungkan, terutama untuk bidang ekonomi dan politik. Masyarakat dunia kini sedang menghadapi tujuan-tujuan baru yang memukau dan mengkhawatirkan.

Perspektif global berakar pada ilmuilmu: antropologi, psikologi, sejarah, 
ekonomi, geografi dunia, dan politik, bertujuan untuk menumbuhkan dan meningkatkan kesadaran sebagai warga dunia yang berpartisipasi aktif.

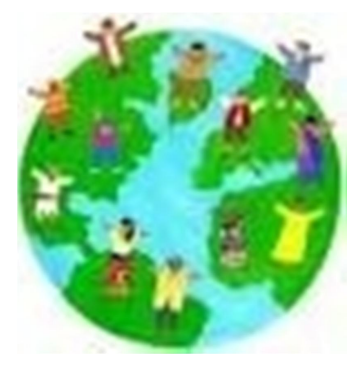

Sumber : Wikipedia.com, global edu. diunduh, 30/01/14

Pada era globalisasi kecenderungan yang kuat adalah proses terjadinya universalisasi yang melanda seluruh aspek kehidupan manusia. Salah satu implikasi penyeragaman terlihat dengan munculnya gaya hidup global seperti makanan, pakaian dan musik.

John Naisbitt yang terkenal dengan bukunya yang berjudul "Megatrend 2000" menyebutkan bahwa pada tahun-tahun tersebut akan terjadi proses globalisasi melalui teknologi informasi, ada tiga mode yang diterima oleh banyak orang yaitu: makanan (food), pakaian (fashion), dan hiburan (entertainment). Di Indonesia sendiri sudah terjadi proses globalisasi tersebut. Seperti anak-anak kecil yang sudah tahu apa itu KFC, MC Donals, jeans, dan film-film dari berbagai negara. Bahkan mereka lebih senang memilih produk luar negeri tersebut dibandingkan dengan produk-produk buatan negeri sendiri. Media televisi telah mempercepat arus informasi dan membawa kita terlibat dalam informasi dunia. Keadaan ini membuat kita mau tidak mau ikut terlibat dalam pergaulan masyarakat dunia melalui media informasi dan produk industry.
Futurolog lainnya yaitu Alvin Toffler (1972) dalam bukunya yang terkenal "future schock" bahkan lebih dulu telah meramalkan akan terjadinya perubahanperubahan besar dalam kehidupan masyarakat dunia umumnya dan masyarakat industri pada khususnya. Disusul kemudian dengan buku berikutnya yang berjudul the third wave pada tahun 1980, menggambarkan perubahan dunia yang meliputi tiga gelombang yaitu gelombang pertama (the first wave) atau dikenal dengan "revolusi hijau" dimulai sekitar 8.000 tahun SM. Selanjutnya gelombang kedua (the second wave) ditandai dengan revolusi industri pada abab XVII yang membawa perubahan besar disbanding periode kehidupan sebelumnya. Kemudian pada abad XX sebagai gelombang ketiga (the third wave) ditandai dengan kemajuan teknologi informasi dan komunikasi. Gelombang ini dikenal dengan "revolusi informasi".

Berkaitan dengan itu. Kirkwood (2001), menjelaskan bahwa "these students will face a new world order thereby creating a need to acquire a global education. He states.

Their daily contacts will include individuals from diverse ethnic, gender, linguistic, racial, and socioeconomic backgrounds. They will experience some of history's most serious health problems, inequities among less-developed and more-developed nations, environmental deterioration, overpopulation transnational migrations, ethnic nationalism, and the decline of the nation-state. (Kirkwood, 2001, p. 2)

Menurut Kirkwood (2001), siswa akan dihadapkan pada dunia tanpa batas, sehingga diperlukan pendidikan global dalam upaya mengarahkan pada kesadaran global. Sejalan dengan itu, Werner and Case (1997:177), 
menegaskan bahwa : movements to promote a global perspective within social studies are due to the state of the planet as a whole and an understanding of how its systems political, cultural, economic, ecological, and technological - are linked and how these are manifested in relationships. ....."global education has been associated with curriculum reform advocating a more global perspective on the world. A need exists for students to examine the world from varying perspectives and to become aware of the complex interrelationships that characterize $i t^{\prime \prime}$.

Dalam pandangan tersebut mengandung arti yang sama dengan Kirkwood, pada dasarnya pendidikan global itu bagaimana keterhubungan antara berbagaia aspek dalam kehidupan baik system politik, budaya, ekonomi, teknologi maupun lingkungan itu berkaitan dengan kurikulum dalam perspektif global dimanifestasikan.

\section{1) Dimensi-dimensi Pemikiran Perspektif Global}

National Council for the Social Studies (NCSS) pada tahun 1982 menunjukkan arti pentingnya perspektif global diajarkan di sekolah-sekolah:

a. Sekarang kita hidup dalam masa terjadinya peningkatan globalisasi yang ditandai dengan fenomena hampir semua orang berinteraksi secara transnasional (tidak hanya terbatas dalam negaranya saja), multi cultural (dalam berbagai macam budaya) dan cross-cultural (berinteraksi dengan budaya lain selain yang dimilikinya).

b. Aktor-aktor yang berinteraksi dalam tingkat dunia tidak hanya terbatas pada aktor-aktor negara saja, namun juga melibatkan perseorangan, kelompokkelompok lokal, organisasi-organisasi yang bergerak dalam bidang teknologi dan ilmu, perdagangan, perusahaan multi nasional, serta organisasi regional. Mereka ini semakin aktif berinteraksi dan mampu mempengaruhi peristiwaperistiwa lokal maupun global.

c. Kehidupan umat manusia tergantung pada suatu lingkungan fisik dunia yang ditandai dengan terbatasnya sumbersumber alam. Ekosistem dunia akan mempengaruhi dan dipengaruhi oleh umat manusia.

d. Ada keterkaitan antara apa yang dilakukan manusia di bidang sosial, politik, ekonomi, teknologi, pada masa kini dengan masa depan umat manusia yang hidup di bumi ini beserta lingkungan fisiknya di masa yang akan datang.

e. Terjadinya globalisasi yang melibatkan hampir seluruh umat manusia ini menyebabkan masing-masing individu dan seluruh masyarakat berkesempatan dan bertanggung jawab untuk berperan serta dalam meningkatkan lingkungan fisik maupun sosial dunia.

Robert Hanvey dalam bukunya yang sangat terkenal "An Attainable Global Perspective" (1976 )menyebutkan lima dimensi dari perspektif global: Perspective consciousness, State of planet awareness, Cross-cultural awareness, Systemic awareness, Options for partipation.

James Becker, sebagai pelopor perspektif global dalam artikelnya yang berjudul "The World and the School. A case for world centered education"(1979) menyatakan bahwa perspektif global harus menggugah kesadaran murid selaku anggota masyarakat dunia dan juga pada tingkatan masyarakat lainnya. Christine I Bennett dalam bukunya "Comprehensive Multicultural Education:Theory and Practice" (1995) menyatakan bahwa para pendidik harus mempersiapkan murid-murid sebagai penerus generasi di masa datang kaya pengetahuan, sikap dan kemampuan yang diperlukan untuk berpartisipasi aktif sebagai warga masyarakat di seluruh lapisan sampai tingkat dunia. Agar anak 
didik menjadi insan yang mempunyai tanggung jawab global, karena mereka merupakan warga negara dunia. Mereka perlu dilatih untuk berpikir global dan bertindak secara lokal atau" think globally act locally".

Merryfield dalam artikelnya yang berjudul "Institutuinalizing Cross-cultural Experiences and Interntional Expertise in Teacher Educational : the Development and Potential of a Global Education PDS Network" (1995) menyimpulkan konsepkonsep dari perspektif global, yaitu bahwa para guru perlu mempunyai pengetahuan dan kemampuan untuk mengajarkan kepada muridnya:

a. Penghargaan terhadap adanya perbedaan-perbedaan dan persamaan budaya, untuk itu para guru perlu mengajarkan berbagai macam perspektif yang dimiliki orang lain ataupun masyarakat lain dan mereka perlu juga mempunyai kesadaran untuk bertoleransi terhadap perspektif yang dimiliki orang lain.

b. Dunia ini merupakan sebuah sistem sehingga di dalamnya terjadi saling ketergantungan dan saling berkaitan.

c. Keputusan-keputusan dan tindakan yang diambil oleh seseorang akan dapat mempengaruhi dan dipengaruhi oleh intraksi global.

Tye and Tye berpendapat bahwa perspektif global meliputi:

a. Studi tentang masalah-masalah dan isuisu yang melintasi batas-batas nasional dan adanya keterkaitan dalam sistemsistem ekonomi, lingkungan, budaya, politik serta teknologi.

b. Peningkatan saling pengertian terhadap budaya lain sehingga si pembelajar mampu mengembangkan kemampuannya untuk bertoleransi terhadap pihak lain dan berempati.

Muessig dan Gilliom dalam bukunya "Perspective of global Education: A source book for classroom teachers" (1981) menyebutkan bahwa melalui perspektif global akan membebaskan para pembelajar dari keinginan-keinginan yang sifatnya parokial (picik/sempit) dan chauvinisme Dengan belajar perspektif global mereka akan mampu berinteraksi secara harmonis dalam masyarakat dunia yang ditunjukkan dengan adanya kemampuan berempati dan mempunyai sifat altruisme (mengutamakan kepentingan orang lain, kalau perlu dengan mengeluarkan pengorbanan).

Menurut American Association of College for Teacher Education (1983) Global education didefinisikan sebagai "the proses by which people acquire a global perspective to explain events ini recognition of the increasing interdependence of nations and cultures" (Retnaningsih, 1998/1999: 1520).

Menurut Hoopes ( Garsia : 1977) mengatakan bahwa pendidikan global mempersiapkan siswa untuk memehami dan mengatasi adanya ketergantugan global dan keragaman budaya, yang mencangkup hubungan, kejadian, dan kekuatan yang tidak dapat diisikan kedalam batas-batas negara dan budaya.

Selanjutnya Hoops, menjelaskan pendidikan global memiliki 3 tujuan yaitu:

a. Pendidikan global memberikan pengalaman yang mengurangi rasa kedaerahan dan kesukuan. Tujuan ini dapat dicapai melalui mengajarkan bahan dan mengunakan metode yang memberikan relatifisme budaya.

b. Pendidikan global memberikan pengalaman yang mempersiapkan siswa untuk mendekatkan diri dengan keragaman global. Kegunaan dari tujuan ini adalah untuk mendiskusikan trntang relatifisme budaya da keutamaan etika.

c. Pendidikan global memberikan pengalaman tentang mengajar siswa untuk berfikir tentang mereka sendiri 
sebagai individu, sebagai suatu warga negara dan sebagai anggota masyarakat manusia secara keseluruhan.

Sementara IOWA Department of

Education, menjelaskan bahwa pendidikan global itu :

a. is an approach to learning which promotes greater understanding of the world as an interconnected aggregate of human and natural systems. These systems operate within a single planetary lifesupport system, on which the destiny of all humankind depends.

b. The purpose of global education is to promote long term human by developing greater respect for and greater concern for the environment on which we depend for our very existence.

c. The mission of global education is to produce citizens who are both knowledgeable about the world, and who possess skills, values, and a process commitment appropriate for the support of quality long-term survival of all human beings.

Berdasarkan tujuan tersebut maka, peran guru adalah :

a. Memberikan bekal pengetahuan kepada siswa tentang pentingnya pengetahuan global dalam memahami masalahmasalah tertentu.

b. Meningkatkan kesadaran dan wawasan anak didik sebagai landasan dalam melakukan tindakan yang berdampak global.

c. Memberikan contoh dan teladan dalam aktivitas sehari-hari, yang mempunyai pengaruh terhadap masalah global.

Saat ini tidak ada suatu bangsapun yang statis dan homogen. Setiap bangsa berkembang karena adanya interaksi dengan bangsa lain, sehingga sistem nilai budaya dan nilai lainnya akan saling mempengaruhi satu sama lain. Perspektif global bertolak dari masalah yang ada dalam kehidupan sehari-hari, misalnya mengenai masalah pendidikan, kesehatan, pengangguran, kemiskinan, dan sebagainya. Semua permasalahan ini berdampak pada permasalahan global.

Dalam kaitannya dengan budaya di era globalisasi, Makagiansar (Mimbar, 1990) mengajukan empat dimensi perspektif global, yaitu:

a. Afirmasi atau penegasan dari dimensi budaya dalam proses pembangunan bangsa dan masyarakat. Pembangunan akan terasa hampa jika tidak diilhami oleh kebudayaan bangsanya. Nilai budaya suatu bangsa menjadi landasan bagi pembangunan suatu negara, serta merupakan alat seleksi bagi pengaruh luar yang sudah tidak terkendali.

b. Mengembangkan identitas budaya dan setiap kelompok manusia berhak diakui identitas budayanya.

c. Partisipasi, bahwa dalam pengembangan suatu bangsa dan negara sangat diperlukan partisipasi dari masyarakat.

d. Memajukan kerjasama antar budaya. Hal ini dimaksudkan agar ada aksi dan upaya saling mengisi atau mengilhami, sehingga akan ada kemajuan dan peningkatan antar budaya bangsa.

Menurut Khan (2010:xv) "ecopedagogy movement is an important effort to ensure that environmental education becomes an integral part of the school curriculum. Dengan demikian bahwa konsep penyadaran global perlu dibangun secara formal juga di sekolah dengan cara memasukannya dalam kurikulum.

\section{2) Upaya Memanfaatkan Isu-isu Perspektif Global dalam Global Awareness \\ Secara politis peran negara bergeser} dari penentu dan pembuat wawasan kebangsaan menjadi penjaga stabilitas dan pengontrol politik baik di dalam maupun 
luar negeri. Perlu disadari bahwa negara kita berhadapan dengan faktor luar yang sangat kuat. Oleh karena itu, peningkatan kerja sama dengan negara lain dalam segala bidang perlu ditingkatkan. Negara harus bersifat terbuka, karena kerja sama dalam berbagai bidang menuntut adanya komitmen yang tinggi. Negara harus beradaptasi dengan sistem yang terus berubah, aktif mengikuti dan mengadakan perubahan. Berikut ini beberapa manfaat mempelajari perspektif global :

a. Meningkatkan wawasan dan kesadaran para pendidik dan peserta didik bahwa kita bukan hanya penghuni satu daerah, tetapi mempunyai ketergantungan dengan orang lain di belahan bumi yang lain. Oleh karena itu sikap kita harus mencerminkan "sikap ketergantungan" tersebut.

b. Menambah dan memperluas pengetahuan kita tentang dunia, sehingga dapat megikuti perkembangan dunia dalam berbagai aspek terutama perkembangan IPTEK.

c. Mengkondisikan para mahasiswa untuk berpikir integral bukan general, sehingga suatu gejala atau masalah dapat ditanggulangi dari berbagai aspek.

d. Melatih kepekaan dan kepedulian mahasiswa terhadap perkembangan dunia dengan segala aspeknya.

Lee Anderson dan Charlotte Anderson (1979) menyatakan bahwa untuk mempersiapkan peserta didik agar menjadi warga negara yang baik harus dimulai dari berbagai macam kelompok yang melibatkannya, dari yang terdekat hingga yang terjauh, yaitu dari masyarakat lokal, nasional, hingga global. Ada 5 tujuan pokok dari perspektif global, yaitu:

a. Mengembangkan pengertian keberadaan mereka sebagai individu-individu yang membentuk masyarakat. b. Mengembangkan pengertian bahwa mereka merupakan anggota dari masyarakat dunia.

c. Mengembangkan pengertian bahwa mereka adalah penghuni planet bumi ini dan kehidupannya bergantung pada planet bumi tersebut.

d. Peserta didik harus diberi pengertian bahwa mereka adalah partisipan atau pelaku aktif dalam masyarakat global ini.

e. Mendidik peserta didik agar mempunyai kemampuan untuk hidup secara bijaksana dan bertanggung jawab sebagai individu, sebagai umat manusia, sebagai insan penghuni planet bumi ini, serta sebagai anggota masyarakat global.

Sementara itu, menurut Marryfield (dalam Nursid dan Kuswaya, 1997), tujuan diberikannya perspektif global adalah sebagai berikut:

a. Mendorong mahasiswa untuk mempelajari lebih banyak tentang materi dan masalah yang berkaitan dengan masalah global.

b. Mendorong para pendidik untuk mempelajari masalah yang berkaitan dengan masalah lintas budaya.

c. Mengembangkan dan memahami makna perspektif global baik dalam kehidupan sehari-hari maupun pengembangan profesinya.

Berkaitan dengan masalah global,

Merry M. Merryfield (1997:8) mengemukakan pokok-pokok masalah global, yaitu: penduduk dan keluarga berencana (population and family planning); hak rakyat menentukan pemerintahan sendiri (self-determination); pembangunan (development); hak asasi manusia (human right); emigrasi, imigrasi dan pengungsian (emigration, immigration and refugees); kepemilikan bersama secara global (the global commnos); lingkungan hidup dan sumber daya alam (environment and natural 
resources); persebaran kemakmuran; teknologi informasi; sumber daya; jalan masuk ke pasar; kelaparan dan bahan pangan; perdamaian dan keamanan; prasangka dan diskriminasi.

Isu dan masalah diatas bukan lagi hanya dirasakan secara lokal dan regional di tempat-tempat serta kawasan-kawasan tertentu, melainkan telah menjadi isu dan masalah global yang dirasakan serta disadari oleh masyarakat dunia. Badan dan lembaga dunia, baik organisasi yang merupakan bagian dari PBB maupun diluar PBB seperti LSM (lembaga swadaya masyarakat), telah menaruh perhatian serta kepedulian terhadap masalah-masalah global tersebut.

Berdasarkan itu pula, maka isu-isu global banyak memberikan kontribusi juga bagi upaya membangun saling ketergantungan antar bangsa di dunia ini, sehingga ketika semua bangsa menyadari akan ketergantungan tersebut, maka secara tidak langsung dan langsung mereka akan menyadari arti penting "Global Awareness" dalam hidupnya.

Konteks pembelajaran PKn tidak bisa dilepaskan dari konteks masyarakat secara global sebagai objek studinya, begitu juga dengan IPS sebagai integrasi atau penyederhanaan dari ilmu-ilmu social yang ditujukan untuk program pendidikan memiliki objek yang sama yaitu masyarakat, maka PKn dan IPS tidak bisa dilepaskan dari konteks masyarakat global. PIPS dapat diartikan dengan "penelaahan atau kajian tentang masyarakat". Dalam mengkaji masyarakat, guru dapat melakukan kajian dari berbagai perspektif sosial, seperti kajian melalui pengajaran sejarah, geografi, ekonomi, sosiologi, antropologi, politikpemerintahan, dan aspek psikologi sosial yang disederhanakan untuk mencapai tujuan pembelajaran.

\section{Konseptualisasi Karakter Sosial Peserta didik}

Coon (1983) mendefinisikan karakter sebagai suatu penilaian subyektif terhadap kepribadian seseorang yang berkaitan dengan atribut kepribadian yang dapat atau tidak dapat diterima oleh masyarakat. Sedangkan Lickona (1991), karakter akan berhubungan dengan moral knowing, moral loving (valueing) and moral behavior (doing). Dan menurut Rudd (1998) Character was defined as the possession of moral values, social values or both.

Menurut (Ditjen Mandikdasmen 2010 - Kementerian Pendidikan Nasional), Karakter adalah :

cara berpikir dan berperilaku yang menjadi ciri khas tiap individu untuk hidup dan bekerjasama, baik dalam lingkup keluarga, masyarakat, bangsa dan negara. Individu yang berkarakter baik adalah individu yang bisa membuat keputusan dan siap mempertanggungjawabkan tiap akibat dari keputusan yang ia buat.

Lebih jauh substansi karakter Lickona dan Ryan/Bohlin (1991) menjelaskan antara lain:

Pertama, Knowing of good atau moral memiliki enam unsure (yang harus diajarkan kepada peserta didik untuk mengisi ranah pengetahuan), yaitu: 1) kesadaran moral; 2) Pengetahuan tentang nilai-nilai moral; 3) Penentuan sudut pandang; 4) Keberanian menentukan sikap; dan 6) Pengenalan diri.

Kedua,moral loving atau loving the good adalah penguatan aspek emosipeserta didik untuk menjadi manusia berkarakter, yang meliputi: 1) Percaya diri; 2) Kepekaan terhadap derita orang lain; 3) Pengendalian diri; dan 4) Kerendahan hati.

Ketiga, moral doing atau doing the good adalah bagaimana membawa diri atau peserta didik dalam 
berinteraksi antara satu sama lain dalam lapangan social, dalam arti bagaimana mengimplementasikan terhadap apa yang diketahui dan dicintai yang terkait dengan kebaikan-kebaikan. Tentunya yang diharapkan disini adalah bagaiamana diri sendiri atau peserta didik memberikan manfaat yang sebesarbesarnya kepada orang dalam pergaulan sosial.

Terkait dengan definisi karakter di atas, terkandung makna pendidikan "karakter sosial". Moral loving (values) dan moral doing doing the good sangat erat kaitanya dengan pembentukan karakter sosial, menyangkut kepedulian dan cinta kasih terhadap orang lain. Pembentukan karakter sosial ini menjadi penting dalam menghasikan peserta didik yang mampu hidup bersama, tertib, aman dan nyaman dengan toleransi yang tinggi sehingga mencerminkan kehidupan masyarakat demokratis. Karakter sosial dalam Wikipedia.org dijelaskan sebagai :

sifat-sifat yang kita tampilkan dalam hubungan kita dengan orang lain (ramah atau

ketus, ekstrovert atau introvert, banyak bicara atau pendiam, penuh perhatian atau tidak pedulian, dsb). Hal hal ini memengaruhi peran sosial kita, yaitu segala sesuatu yang mencakup hubungan dengan orang lain dan dalam masyarakat tertentu.

Seperti dijelaskan Fromm(1955) yang mengemukakan bahwa :

karakter sosial dalam kelompok masyarakat dimana manusia berhubungan satu sama lain dengan penuh cinta, dimana ia berakar dalam ikatan-ikatan persaudaraan dan solidaritas, suatu masyarakat yang memberinya kemungkinan untuk mengatasi kodratnya dengan menciptakannya bukan dengan membinasakannya, dimana setiap orang mencapai pengertian tentang diri untuk menjadi manusiawi sepenuhnya.

Hasil penelitian Fromm, 1955 : 85) tentang social character menjelaskan bahwa karakter sosial, yaitu membentuk kekuatankekuatan manusiawi dalam masyarakat tertentu dengan tujuan memfungsikan masyarakat secara berkesinambungan menuju masyarakat demokratis dan manusiawi. Dalam dunia sekolah, tentu masyarakat itu adalah seluruh peserta didik yang akan menjadi generasi bangsa ke depan yang seharusnya disiapkan bagi tegaknya pembangunan karakter bangsa ini. Indikator dari karakter sosial yang dikembangkan di sekolah itu antara lain kerjasama, toleransi, menghargai dan menghormati sesama, kepedulian atau solidaritas.

Karakter sosial merupakan perwujudan kepribadian yang melambangkan kualitas karakter bangsa yang baik seperti mewujudkan sikap toleransi, menghormati, menghargai, kebersamaan, gotong-royong serta kepedulian dan kepekaan terhadap sesama. Kekerasan, anarkhisme, tawuran antar pelajar, genk motor, pelecehan seksual, bullying dan lainya memberikan indikasi bahwa karakter sosial yang lemah dan bahkan memudar pada kepribadian remaja Indonesia khususnya kalangan pelajar.

Karakter sosial, seperti juga kualitas diri yang lainnya, tidak berkembang dengan sendirinya. Perkembangan karakter sosial pada setiap individu dipengaruhi oleh faktor bawaan (nature) dan faktor lingkungan (nurture). Menurut para developmental psychologist, setiap manusia memiliki potensi bawaan yang akan termanisfestasi setelah dia dilahirkan, termasuk potensi yang terkait dengan karakter atau nilai-nilai kebajikan. Dalam hal ini, Confusius seorang filsuf terkenal Cina menyatakan bahwa 
manusia pada dasarnya memiliki potensi mencintai kebajikan, namun bila potensi ini tidak diikuti dengan pendidikan dan sosialisasi setelah manusia dilahirkan, maka manusia dapat berubah menjadi binatang, bahkan lebih buruk lagi (Megawangi, 2003.hlm.32). Oleh karena itu, sosialisasi dan pendidikan anak yang berkaitan dengan nilai-nilai kebajikan baik di keluarga, sekolah, maupun lingkungan yang lebih luas sangat penting dalam pembentukan karakter sosial seorang anak.

Faktor yang mempengaruhi pembentukan karakter sosial seseorang terdiri dari: (1) faktor genetika atau bawaan dari lahir; dan (2) faktor lingkungan. Faktor genetika atau bawaan dari lahir yaitu segala sesuatu yang telah dibawa sejak lahir, baik yang bersifat kejiwaan maupun ketubuhan (fisik). Faktor lingkungan adalah sesuatu yang ada diluar manusia, baik hidup maupun mati. Seperti dijelaskan Yusuf (2007.hlm. 20-31) bahwa :

faktor yang mempengaruhi pembentukan karakter seseorang terdiri atas pengaruh genetika atau pembawaan dan pengaruh lingkungan, sedangkan lingkungan yang mempengaruhinya ialah lingkungan pendidikan, lingkungan keluarga, lingkungan kebudayaan, dan lingkungan sosial-kelompok.

Faktor lingkungan pendidikan menjadi salah satu yang berpengaruh terhadap pembentukan karakter sosial peserta didik disamping faktor lingkungan dan yang lainnya. Sekolah sebagai lembaga pendidikan formal yang dipercaya masyarakat untuk mendidik putra-putrinya, selain memberikan bekal ilmu pengetahuan, teknologi dan seni (IPTEKS) hendaknya juga mampu mengembangkan aspek-aspek nilai moral dan keagamaan dalam rangka pembentukan sikap dan perilaku generasi bangsa yang berbudi pekerti luhur (berakhlak mulia), sehingga mampu menjadi bangsa yang beradab dan bermartabat.

\section{Kesimpulan}

Pendidikan dalam perspektif global yang lebih banyak dipengaruhi oleh perkembangan teknologi informasi sehingga menjamurnya cyber media yang tidak bisa hindari lagi harus dimanfaatkan oleh sekolah dan lembaga pendidikan yang ada agar menjadi khasanah pembentukan karakter peserta didik tanpa mengecilkan peran cyber media dan tidak mengorbankan nilai-nilai kehidupan sosial yang ada.

Secara teknis, strategi pengembangan sikap dan perilaku peserta didik yang berkarakter dalam kegiatan pembelajaran di sekolah setidaknya dapat ditempuh melalui empat alternatif strategi secara terpadu. Strategi pertama ialah dengan mengintegrasikan konten kurikulum pembelajaran berkarakter yang telah dirumuskan ke dalam seluruh mata pelajaran yang relevan, terutama mata pelajaran agama, kewarganegaraan, sosial dan bahasa. Strategi kedua ialah dengan mengintegrasikan pembelajaran berkarakter ke dalam kegiatan sehari-hari di sekolah. Strategi ketiga ialah dengan mengintegrasikan pembelajaran berkarakter ke dalam kegiatan yang diprogramkan atau direncanakan. Dan strategi keempat ialah dengan membangun komunikasi dan kerjasama antara sekolah dengan orang tua peserta didik.

Karakter sosial merupakan bagian dari pendidikan karakter yang mengisyaratkan terbentuknya nilai-nilai manusiawi bagi personal manusia. Karakter sosial ini menjadi penting adanya sebab menyangkut kegiatan interaksi antar personal manusia dalam kehidupannya. Karakter sosial yang terbentuk dalam personal manusia akan membekali mereka untuk dapat hidup berdampingan penuh rasa kasih sayang, saling menghargai, 
demokratis, saling bekerjasama, damai dan saling memperhatikan.

\section{Daftar Pustaka}

Alwi Dahlan. M. 1996. Globalisasi Wawasan, Komunikasi, dan Informasi : Tantangan Akademisi Masa Depan. Jakarta : BP-7 Pusat

Bank, J.A. (1977). Teaching Strategies for The Social Studies- Inquiry, Valueing and Decision Making. Seattle University of Washington. Aditions Wesley Publishing Company.

Borba, Michele. 2001. Building Moral Intelligence. San Fransisco : Jossey Bass

Clark, HL. 1972. Teaching Social Studies In The Secondary Schools. Newyork: Macmillan Pub.

Diaz, Carlos \& Massialas, Xanthopaulus. 1999. Global Perspective for Educator. Boston : Allyn and Bacon

Hahn, Carole L. 1998. Becoming Political. Comparative Perspectives on Citizenship Edcation. New York : SUNY Press

Haworth, R. (2004). Are There Differences in Moral and Social Character Between High School Athletes and Non-athletes. US : UMI.

Hurlock, E.B. ( 1992). Perkembangan Anak. Jakarta: Erlangga.

Hebert, JL; Murphy, W. 1971. Structure In The Social Studies. Washington DC: NCSS.

Korten, David. 1993. Getting to the Twenty First Century : Voluntary Action and The Global Agenda. Alih bahasa : Lilian Tejasudhana. Jakarta : Yayasan Obor Indonesia \& Pustaka Sinar Harapan

Kementerian Pendidikan Nasional. (2010). Ditjen Mandikdasmen.
Pendidikan Karakter di SMP. Direktorat pembinaan SMP

Lickona.1991.Educating for Character; How Our School Can Teach Respect and Responsibility.Bantan Books,New York

Lickona.2003.CEP's Eleven Principles of Effecive Character Education.Washington:nCharacter Education Partnership.

Musfiroh,Tadkiroatun.2008.Pengembangan Karakter Anak Melalui Pendidikan Karakter. Tinjauan Beberapa Aspek Character Building.Yogyakarta: Kerjasama Lembaga Penelitian Unversitas Negeri Yogyakarta dan Tiara Wacana

Michael W. Beets, et.al. (2009) Use of a Social and Character Development Program to Prevent Substance Use, Violent Behaviors, and Sexual Activity Among Elementary-School Students in Hawaii American Journal of Public Health, August 2009, Vol 99, No. 8

NCSS. (1997) Fostering civic virtue: Character education in the social studies NCSS Task Force on Character Education in the Social Studies Social Education; Apr/May 1997; 61, 4; ProQuest Research Library pg. 225

NCSS., (1994). Curriculum Standars for the Social Studies. Washington D.C.: National Council for the Social Studies.

Poerwito. (1991). Ilmu Pengetahuan Sosial. Malang: PPPG IPS PMP Malang

Peraturan Pemerintah Nomor 19 Tahun 2005 tentang Standar Nasional Pendidikan. Jakarta.

Scorgie, Kate (2002) The Power of Social Skills in Character Development: Helping Diverse Learners Succeed Childhood Education; Spring; 78, 3; ProQuest Research Library pg. 177. 
Sigita Burvytė \& Aldona Palujanskienè, 2012 The Possibilities of Children and Younger Teenagers' Social Competence Development in Family and at School. Journal of US-China Public Administration, ISSN 1548-6591 may 2012, Vol. 9, No. 5, 578-585.

Supriawan, Dedi \& A. Benyamin Surasega. (1990). Strategi Belajar Mengajar. (Diktat Kuliah). Bandung : FPTKIKIP Bandung.

Sumantri, N. (2001). Menggagas Pembaruan Pendidikan IPS. Bandung : Rosdakarya Remaja.

Sumaatmadja, Nursid. 1998. Manusia dalam Konteks Sosial, Budaya, dan Lingkungan Hidup. Bandung : Alfabeta

Thomas W. Miller, et.al. (2005). Character Education as a Prevention Strategy in School-Related Violence. The Journal of Primary Prevention ( C 2005) DOI: $10.1007 / \mathrm{s} 10935-005-$ 0004-x

Turner, Long. Bowes \& Lott. 1990. Civics : Citizens in Avtion. Columbus, Ohio : Merryl Publishing Company

Tye, Barbara Benham \& Kennet Tye. 1992. Global Education : A Study of Social Change. New York : SUNY Press

Winataputra. US. (2003). Strategi Belajar Mengajar. Jakarta : Pusat Penerbitan Universitas Terbuka.

Wina Senjaya. (2008). Strategi Pembelajaran; Berorientasi Standar Proses Pendidikan. Jakarta : Kencana Prenada Media Group. 